\title{
Human Cardiosphere-Derived Cells from Patients with Chronic Ischaemic Heart Disease Can Be Routinely Expanded from Atrial but Not Epicardial Ventricular Biopsies
}

\author{
Helen H. L. Chan - Zaal Meher Homji • Renata S. M. \\ Gomes $\cdot$ Dominic Sweeney $\cdot$ George N. Thomas • Jun \\ Jie Tan $\cdot$ Huajun Zhang $\cdot$ Filippo Perbellini $\cdot$ Daniel J. \\ Stuckey · Suzanne M. Watt • David Taggart • Kieran \\ Clarke • Enca Martin-Rendon • Carolyn A. Carr
}

Received: 23 April 2012 / Accepted: 14 June 2012 / Published online: 3 July 2012

(C) The Author(s) 2012. This article is published with open access at Springerlink.com

\begin{abstract}
To investigate the effects of age and disease on endogenous cardiac progenitor cells, we obtained right atrial and left ventricular epicardial biopsies from patients $(n=22)$ with chronic ischaemic heart disease and measured doubling time and surface marker expression in explantand cardiosphere-derived cells (EDCs, CDCs). EDCs could be expanded from all atrial biopsy samples, but sufficient cells for cardiosphere culture were obtained from only 8 of 22 ventricular biopsies. EDCs from both atrium and ventricle contained a higher proportion of c-kit+ cells than CDCs, which contained few such cells. There was wide variation in expression of CD90 (atrial CDCs 5-92 \% CD90+; ventricular CDCs 11-89\% CD90+), with atrial CDCs cultured from diabetic patients $(n=4)$ containing 1.6-fold more CD90+ cells
\end{abstract}

Helen H.L. Chan and Zaal Meher Homji contributed equally to this work.

Electronic supplementary material The online version of this article (doi:10.1007/s12265-012-9389-0) contains supplementary material, which is available to authorized users.

H. H. L. Chan · Z. Meher Homji • R. S. M. Gomes · J. J. Tan •

F. Perbellini • D. J. Stuckey $\cdot$ K. Clarke $\cdot$ C. A. Carr $(\bowtie)$

Department of Physiology, Anatomy and Genetics,

University of Oxford,

Sherrington Building, Parks Road,

Oxford OX1 3PT, UK

e-mail: Carolyn.Carr@dpag.ox.ac.uk

D. Sweeney $\cdot$ G. N. Thomas $\cdot$ H. Zhang $\cdot$ S. M. Watt .

E. Martin-Rendon

Stem Cell Research Laboratory, NHS Blood and Transplant, John Radcliffe Hospital,

Oxford, UK than those from non-diabetic patients $(n=18)$. No effect of age or other co-morbidities was detected. Thus, CDCs from atrial biopsies may vary in their therapeutic potential.

Keywords Cardiosphere-derived cells · Ischaemic heart disease $\cdot$ Diabetes $\cdot$ Human

\section{Introduction}

Cardiovascular disease remains the leading cause of death in the Western world [1]. Cardiac stem/progenitor cells, identified in the heart in 2003 [2, 3], are primed to repair damaged myocardium. To provide sufficient cells for
D. Sweeney $\cdot$ G. N. Thomas $\cdot$ S. M. Watt $\cdot$ E. Martin-Rendon Nuffield Department of Clinical Laboratory Sciences, University of Oxford, John Radcliffe Hospital, Oxford, UK

H. Zhang $\cdot$ D. Taggart

Nuffield Department of Surgical Sciences, University of Oxford, John Radcliffe Hospital,

Oxford, UK

Present Address:

J. J. Tan

Advanced Medical and Dental Institute, Universiti Sains Malaysia,

Penang, Malaysia 
therapy, cardiac stem/progenitor cells can be expanded in vitro, by selection using cell surface markers such as c-kit [2] or sca-1 [3], or from explanted biopsies via the formation of cardiospheres $[4,5]$. Stem/progenitor cells isolated using each of these methods have improved cardiac function in animal models $[2,3,5,6]$.

Cardiosphere-derived cells (CDCs) are an heterogeneous population, comprising c-kit+/CD105+ cells, CD90+/ CD105+ cells and a small number of CD31+ and CD34+ progenitor cells [7]. In 2009, Andersen et al. suggested that CDCs did not contain cardiac stem cells but were a combination of cardiac fibroblasts and CD45+ blood-borne cells [8]. However, this was rebutted by Davis et al. [7], who demonstrated that c-kit,$+ \mathrm{CD} 31+/ \mathrm{CD} 34+$ and CD90+ explantderived cells (EDCs) could be cultured from human, mouse, rat and pig hearts and that rat CDCs were clonogenic and exhibited multilineage potential. Furthermore, they showed that human CDCs, when expanded from endomyocardial biopsies and transplanted into the infarcted mouse heart, differentiated into cardiomyocytes, endothelial and smooth muscle cells [9]. However, it is still uncertain whether biopsy location, increasing grades of cardiac failure or the presence of co-morbid risk factors, such as diabetes or hypertension, can affect the number and characteristics of the CDC population. Markers of cell senescence increase with increasing age and with type 1 diabetes in c-kit + cells from human and mouse hearts [10-12], suggesting that this population of the cardiac stem/progenitor cells may be susceptible to damage.

CDCs have recently been tested in a phase 1 clinical trial, in patients 2-4 weeks after acute myocardial infarction (CADUCEUS trial) [13]. Selected c-kit+ progenitor cells have also been tested in patients with ischaemic cardiomyopathy (SCIPIO trial) [14]. As the heart contains few c-kit+ cells (approximately 1 in 10,000 myocytes [2]), it took 3 to 4 months to culture 1 million c-kit+ cells for the SCIPIO trial [14]. The cells were tested to confirm high expression of c-kit and low indicators of senescence. In contrast, for the CADUCEUS trial, 25 million CDCs were cultured in 36 days. The CDCs were assessed by flow cytometry to confirm high expression of CD105 and low numbers of CD45+ cells. The proportion of c-kit + cells was not reported. Despite the higher number of cells administered in the CADUCEUS trial, and a significantly reduced infarct size at 6 months, there was no significant improvement in left ventricular ejection fraction (LVEF). Conversely, the SCIPIO trial showed an improvement in LVEF in patients after 4 months, suggesting that selected c-kit + cells may be more effective than the heterogeneous CDC population.

Here, we cultured CDCs from the atria and ventricles of patients undergoing cardiac bypass surgery to characterise the cell population. We also assessed the effect of increasing severity of cardiac failure, and the existence of co-morbidities, such as diabetes and hypertension, on the number and characteristics of the CDC population obtained.

\section{Materials and Methods}

\section{Biopsy Collection}

Full-thickness right atrial biopsies and left ventricular epicardial biopsies were obtained at the John Radcliffe Hospital, Oxford, from coronary artery bypass graft patients, with informed written consent. Ethical approval was granted by the relevant Research Ethics Committee to obtain cardiac biopsies and conduct this study (REC reference: 07/H0607/95), which was carried out in accordance with the Helsinki Declaration of 1975, as revised in 2000. All human tissue samples and cells were handled, processed and stored under a Human Tissue Authority licence.

\section{Culture of CDCS}

Biopsies were placed in Complete Explant Medium (CEM, see Electronic Supplementary Material) on ice and processed within 2-3 h. Gross connective and adipose tissues were removed to leave only cardiac tissue. After washing twice with phosphate buffered saline (PBS, Invitrogen, UK), the sample was cut into $5-\mathrm{mm}$ segments and digested in $0.05 \%$ trypsin (Invitrogen) for $3 \mathrm{~min}$ at room temperature. The segments were further minced into 1-mm fragments that were washed again in PBS and plated out as explants onto fibronectin-coated (Sigma, USA) 60-mm Petri dishes (Corning, UK) containing $0.5 \mathrm{~mL}$ of CEM. Explants were incubated for $1 \mathrm{~h}$ at room temperature to allow adhesion of explants to the fibronectin coating, before a further $1 \mathrm{~mL}$ of CEM was added. Explants were cultured at $37{ }^{\circ} \mathrm{C}$ in $5 \%$ $\mathrm{CO}_{2}$, with the CEM replaced every 4 days. A layer of long thin fibroblast-like cells spontaneously emerged from edges of adherent explants, followed by overlying round phase bright cells. Phase bright cells were harvested once confluent by washing explants with PBS, with $1 \mathrm{~mL} 0.53 \mathrm{mM}$ EDTA (Versene, Invitrogen), then treating enzymatically with $1 \mathrm{~mL}$ trypsin for $5-7 \mathrm{~min}$ at $37^{\circ} \mathrm{C}$. An additional wash of PBS ensured complete removal of phase bright cells in addition to some fibroblasts. Explants could be harvested twice, allowing 1 week between harvests. Harvested cells were seeded into poly-D-lysine-coated wells at a concentration of $3 \times 10^{5}$ cells in $500 \mu \mathrm{L}$ of Cardiosphere Growth Medium (see Electronic Supplementary Material). Fully formed, loosely adherent cardiospheres were harvested by gentle pipetting and plated onto fibronectin-coated T75 flasks (Corning) for expansion as CDCs to passage 2. 
Flow Cytometry

Once confluent at passage 2, CDCs were harvested using tryp$\sin \left(5 \mathrm{~min}\right.$ at $\left.37^{\circ} \mathrm{C}\right)$ after washing three times with PBS and once with Versene. Non-specific binding of antibodies was blocked using human FcR block (Miltenyi Biotec., Germany) at a concentration of $100 \mu \mathrm{L} / 1 \times 10^{6}$, incubated on ice in the dark for $30 \mathrm{~min}$. Cells were washed, suspended in PBS to a final concentration of $2 \times 10^{6}$ cells $/ \mathrm{mL}$ and incubated with the appropriate antibody (see Electronic Supplementary Material) for flow cytometric analysis using a BD LSRII flow cytometer (BD Biosciences, UK) equipped with UV, blue and red lasers.

\section{Cardiomyogenic Differentiation}

Cardiomyogenic differentiation was induced using cardiomyocyte differentiation medium (CDM) (2\% FBS ESQ (embryonic stem cell-qualified; Invitrogen), $1 \%$ insulin transferrin selenium in IMDM:DMEM/F12 (1:1, Sigma) supplemented with $1 \mathrm{mM}$ dimethyl sulphoxide (DMSO). The DMSOsupplemented CDM was changed every 2 days for 6 days. Then, all cells were aspirated with PBS to remove the dead cells, and $2 \mathrm{ml} \mathrm{CDM}$ supplemented with $0.1 \mathrm{mM}$ ascorbic acid was added to the plate. The medium was changed every 2 days for the following 6 days.

Immunocytochemistry

Conditioned CDCs were grown on Nunc Lab-Tek ${ }^{\circledR}$ 4-well chamber slides precoated with $10 \mu \mathrm{g} / \mathrm{ml}$ fibronectin and fixed with $4 \%$ paraformaldehyde (Sigma) for $10 \mathrm{~min}$ on ice. Fixed cells were blocked with $10 \%$ donkey serum (Biosera, UK) in $0.1 \%$ PBS-tween for an hour at room temperature and then incubated with the primary antibody (see Electronic Supplementary Material) diluted in PBS, overnight at $4{ }^{\circ} \mathrm{C}$ in a humidified chamber. Cells were incubated with the appropriate secondary antibody for an hour at $4{ }^{\circ} \mathrm{C}$ and the immunofluorescence detected using a confocal microscope (Zeiss Confocal LSM 520 META).

For filamentous actin staining, a rhodamine phalloidin probe was used. Cells were permeabilised with $0.1 \%$ Triton after fixation and blocking for 30 min using a solution of $2 \% \mathrm{FBS}+2 \% \mathrm{BSA}$ in PBS. Rhodamine phalloidin (Invitrogen) was diluted in PBS and added to the cells for $15 \mathrm{~min}$ before washing and mounting.

\section{Statistical Analysis}

Data are expressed as means \pm standard error. Analysis of variance, with a Tukey post hoc test, $T$ tests and Pearson correlations were performed using Excel and SPSS software. Statistical significance was assumed to be $p<0.05$.

\section{Results}

Patient Demographics

Full-thickness right atrial biopsies ( $n=22 ; 468 \pm 40 \mathrm{mg})$ and left ventricular epicardial biopsies $(n=22 ; 164 \pm 29 \mathrm{mg})$ were taken from patients undergoing coronary artery bypass surgery (4083 years of age), three of whom underwent concurrent valve replacement. Details of the patient population are given in Table 1.

\section{Cell Culture}

Biopsies were explanted onto fibronectin-coated dishes for culture of explant-derived cells (EDCs). A bed of fibroblastlike cells grew out from the explants, over which phasebright cells migrated. Once confluent, EDCs could be harvested for culture as cardiospheres.

The time taken for each stage of the cell culture process and the number of cells produced varied considerably (Fig. 1a, Table S1). Cardiospheres grow slowly when EDCs are seeded at a low density [15], so at least 40,000 EDCs need to be harvested for successful cardiosphere culture. All atrial biopsies generated sufficient EDCs for cardiosphere formation, over 7 to 55 days, but it was only possible to culture cardiospheres from eight ventricular biopsies (denoted group AV).

There was a significant correlation between the number of EDCs produced from atrial and ventricular biopsies from the same patients (Fig. 1b). The time taken to culture confluent atrial EDCs inversely correlated with the doubling time of the resultant CDCs, in that fast growing EDCs generated fast-growing CDCs (Fig. 1c). The low sample

Table 1 Patients' demographics

Data are $n$ (percent) or mean (SEM)

$B M I$ body mass index, NYHA New York Heart Association

\begin{tabular}{ll}
\hline Age & $67 \pm 2$ \\
BMI & $28 \pm 1$ \\
Sex (male) & $20(91 \%)$ \\
Class I & $1(0.05 \%)$ \\
Class II & $11(50 \%)$ \\
Class III & $7(32 \%)$ \\
Class IV & $2(9 \%)$ \\
Missing & $1(4.5 \%)$ \\
Diabetes & $4(18 \%)$ \\
Smoker & $9(41 \%)$ \\
Hypertension & $15(68 \%)$ \\
High cholesterol & $19(86 \%)$ \\
Aspirin & $15(68) \%$ \\
ACE inhibitors & $12(55) \%$ \\
Beta blockers & $15(68 \%)$ \\
Statins & $20(90 \%)$ \\
\hline
\end{tabular}


Fig. 1 Expansion of EDCs and CDCs from atrial and ventricular biopsies. a Considerable variation was observed in the time taken for culture of confluent explant- and cardiosphere-derived cells and in the number of cells obtained. b The number of EDCs generated from atrial biopsies correlated with the number from ventricular biopsies. c The time taken for atrial EDCs to reach confluence correlated inversely with the doubling time of CDCs a

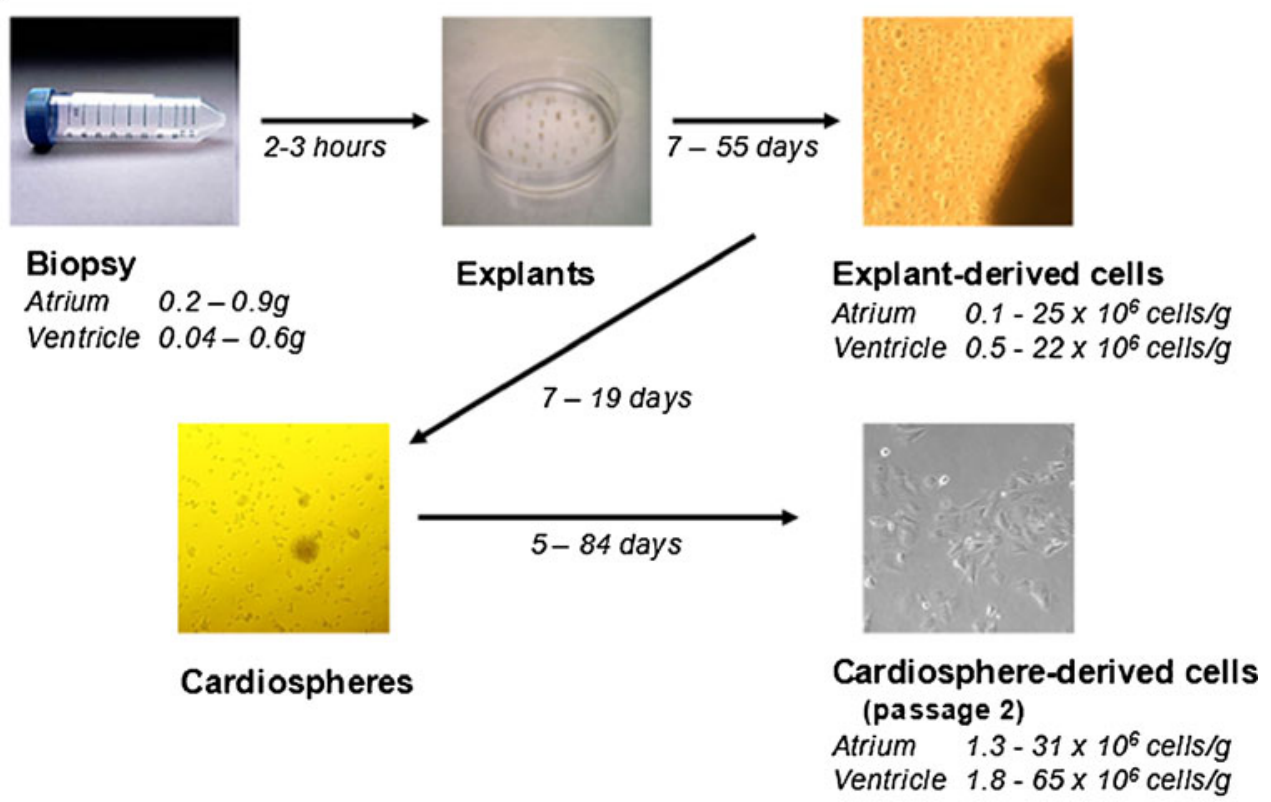

b

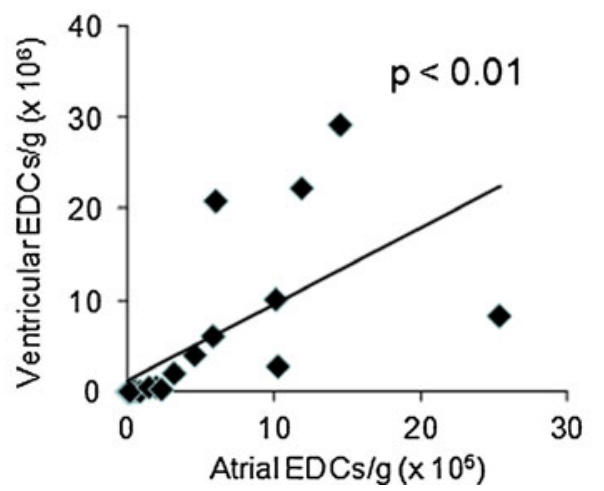

C

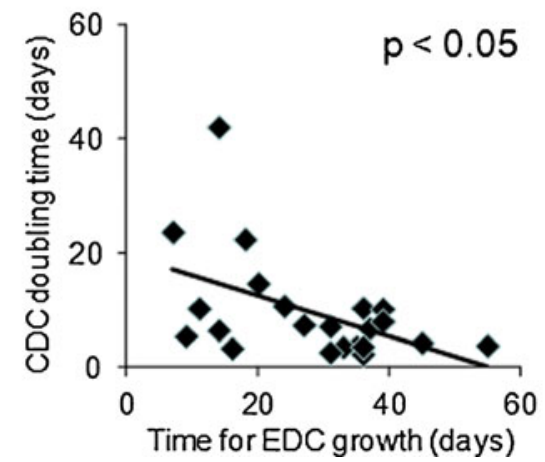

number prevented confirmation of a similar result for ventricular EDCs.

There were no correlations between the rate of growth or the number of EDCs or CDCs with age or disease (Table 2).

\section{EDC and CDC Characterisation}

Cell surface markers on all CDCs $(n=22)$ and a subset of EDCs $(n=3)$ were characterised using flow cytometry (Fig. 2a, b; Tables 2 and 3). EDCs and CDCs comprised predominantly of CD105+ cells, with a wide variation in expression of CD90 (atrial EDCs 26-71 \%, ventricular EDCs 38-70 \%; atrial CDCs 5-92 \% CD90+; ventricular CDCs 11-89\% CD90, Table S1) and with low expression of c-kit, CD31 and CD34. There were significantly more ckit + cells in EDCs than CDCs, from both atrial and ventricular biopsies, and ventricular EDCs contained more c-kit+ cells than atrial EDCs (Fig. 2b; Table 3). EDCs contained $1 \%$ CD45+ cells, which were not detected in the CDC population. There were no other significant differences in expression of cell surface markers in EDCs or CDCs from atrial tissue compared with those from ventricular tissue (Fig. 2b).

The percentage of CD90+ CDCs inversely correlated with the time taken to culture confluent EDCs, indicating that where biopsies produced confluent EDCs relatively rapidly, these EDCs contained more CD90+ cells (Fig. 2c). Predominantly, the atrial biopsies with rapid outgrowth came from hearts from which insufficient ventricular EDCs were produced (denoted group A). CDCs from group A contained $21 \%$ more CD90+ cells than those from group AV (Table 3). Furthermore, the percentage of CD105+ CDCs inversely correlated with the CDC doubling time (Fig. 2d), suggesting that the doubling time of CD105+ cells is faster than that of CD105- cells.

Atrial CDCs from diabetic patients $(n=4)$ contained significantly more CD90+ cells $(79 \pm 8 \%)$ than those from nondiabetic patients $(50 \pm 5 \% ; n=18$; Fig. $2 \mathrm{e})$, but there was no other correlation between age or disease and CDC numbers, doubling time or cell surface markers (Table 2). 


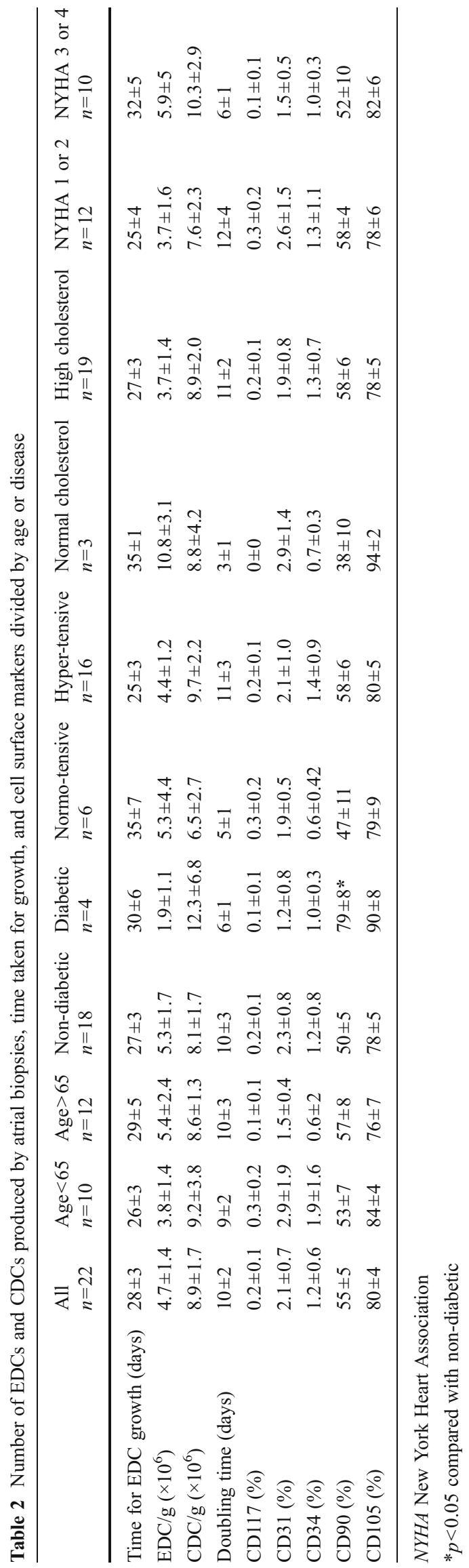

\section{CDC Differentiation}

To further investigate differences between CDCs from diabetic and non-diabetic patients, we treated CDCs from nondiabetic $(n=2)$ or diabetic patients $(n=2)$ with cardiomyogenic differentiation medium for 2 weeks. Untreated and treated CDCs were stained for CD90, the fibroblast marker discoidin domain receptor 2 (DDR2), smooth muscle actin (SMA) and troponin T (TnnT) (Fig. 3). Confirming the flow cytometric analysis, untreated $\mathrm{CDCs}$ from diabetic patients contained more CD90+ cells than those from non-diabetic patients and also contained more cells positive for DDR2. Untreated CDCs also contained cells expressing smooth muscle actin (SMA) but few cells positive for TnnT. Following treatment with cardiomyogenic differentiation medium, there was a decrease in the proportion of cells expressing CD90 and SMA and an increase in the number of cells positive for TnnT, but possibly to a lesser extent in the CDCs from diabetic patients.

\section{Discussion}

Here, we show that CDCs cannot be cultured routinely from ventricular epicardial biopsies from patients with ischaemic heart disease. Furthermore, both atrial and ventricular epicardial CDCs contain variable numbers of CD90+ cells and few c-kit+ cells.

As has been seen with studies in bone marrow stem cells, there is a disparity between results observed in the single human clinical trial using CDCs [13] and those in animal models $[4-6,16]$ where cells were predominantly isolated from young, healthy animals rather than those with heart disease. Additionally, in animal models, there are no potentially confounding pharmacological or surgical treatments, whereas in the clinic, ethical practice mandates that cells be administered in addition to current 'best practice' therapy. Here, we found that CDCs from patients with ischaemic heart disease contained few c-kit + cells and an increased proportion of CD90+ cells than reported originally [5] (Fig. 2). There are now at least 12 papers reporting cell surface markers on cells expanded from human biopsies using the cardiosphere protocol (Table 4), although not all give details of patient age or disease. While there is consensus that the majority of cells are $\mathrm{CD} 105+$, the proportions of c-kit+ and CD90+ cells vary considerably. The effect of comorbid risk factors such as diabetes and hypertension on the types and proportions of cells obtained has not been reported, although it is likely that at least some of the variation results from differences in culture protocols between laboratories, as small changes to the length of time before harvest of EDCs and of culture of cardiospheres may affect the resultant CDC population, even within laboratories $[17,18]$. 
a
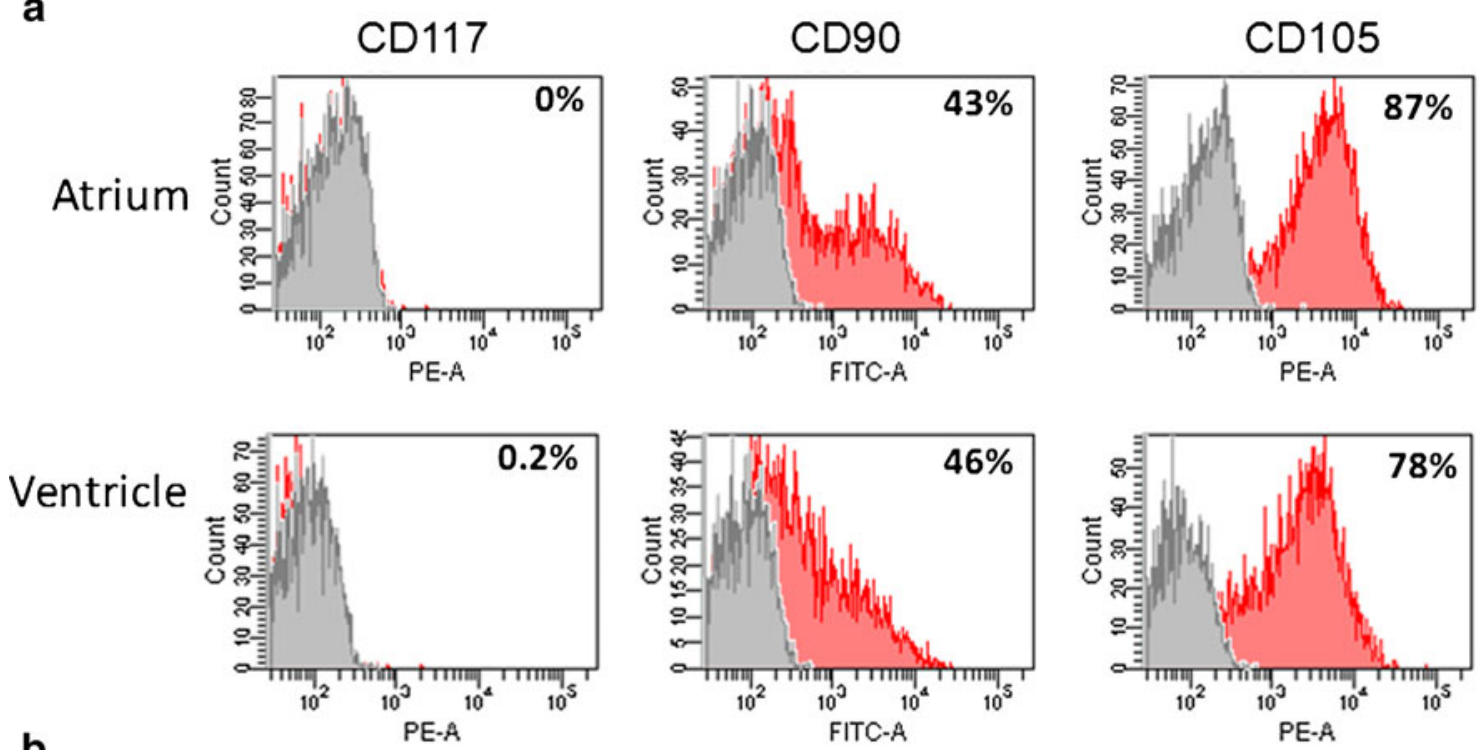

b
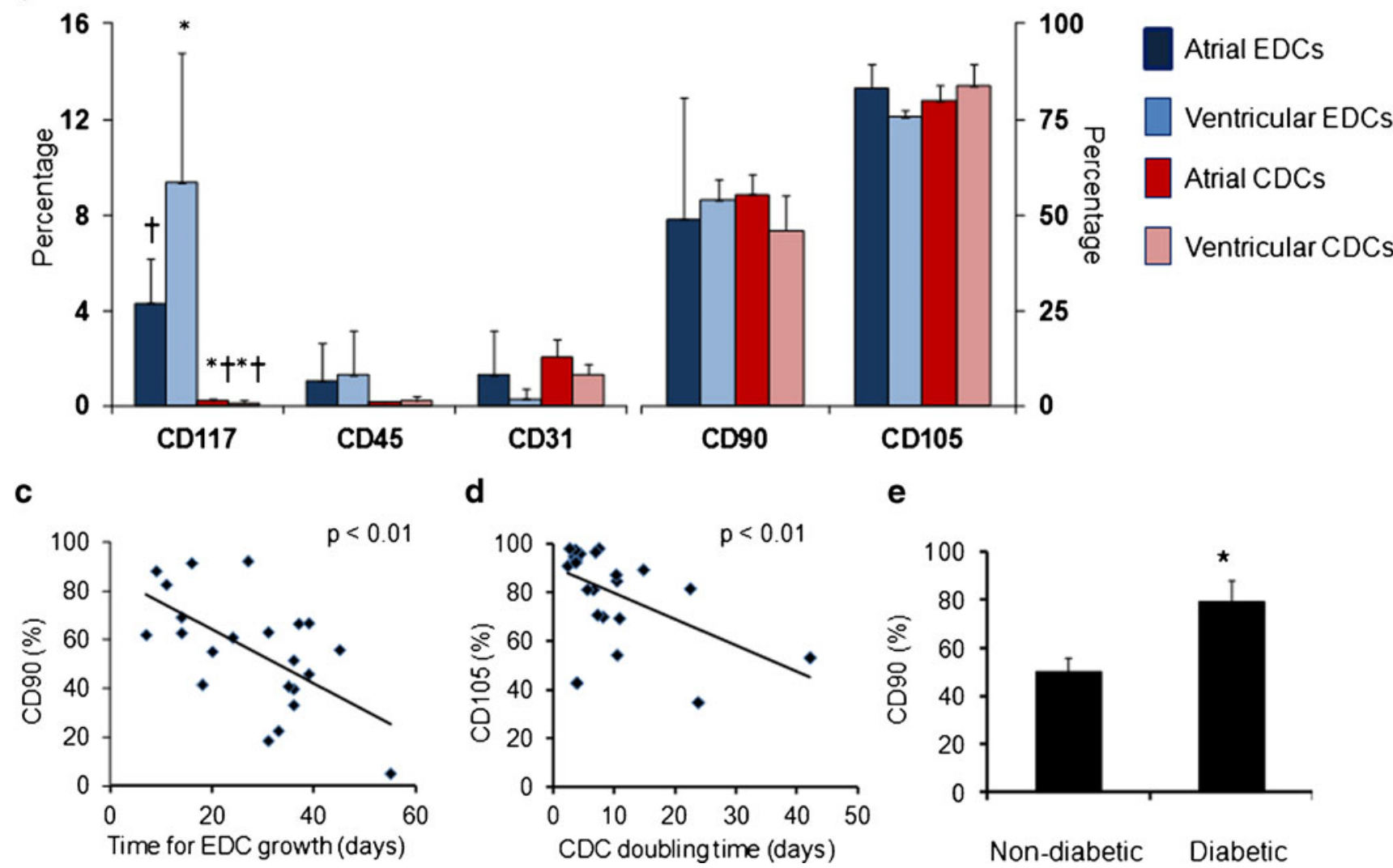

100

d
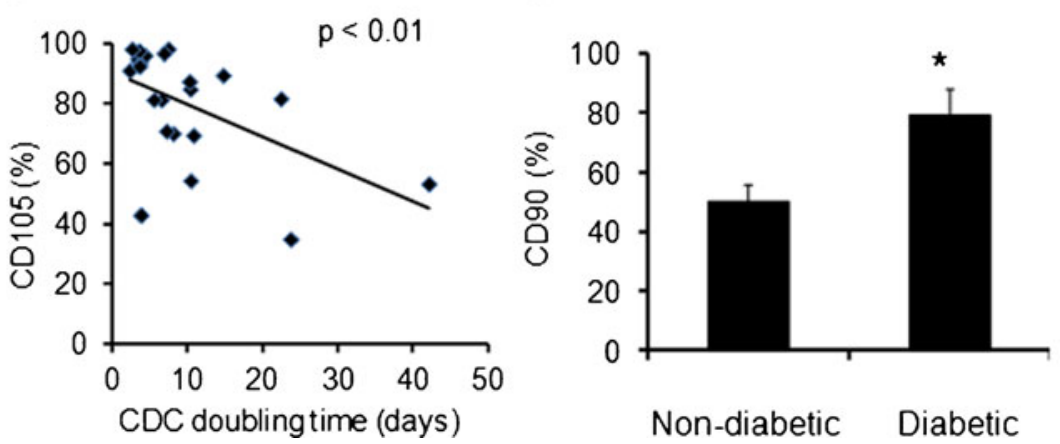

Fig. 2 Cell surface markers on EDCs and CDCs. a Representative flow cytometry plots for CD117 (c-kit), CD90 and CD105 (with isotype controls in grey) in CDCs from atrial (top) and ventricular (bottom) biopsy samples. b Expression of cell surface markers by EDCs and CDCs from atrial and ventricular biopsies $(n=3$ for atrial and ventricular EDCs, $n=22$ for atrial CDCs and 8 for ventricular CDCs; ${ }^{*} p<0.05$ compared with atrial EDCs, $\uparrow p<0.05$ compared with ventricular EDCs). $\mathbf{c}$ The time

It is well documented that c-kit+ cardiac stem/progenitor cells are clonogenic and able to differentiate into cells of the cardiac lineage [19-21]. Human CDCs containing few c-kit+ taken for culture of confluent EDCs inversely correlated with CD90 expression in CDCs and $\mathbf{d}$ the doubling time of CDCs inversely correlated with CD105 expression in CDCs. e Atrial CDCs from diabetic patients $(n=4)$ contained significantly more CD90+ cells than those from non-diabetic patients $(n=18 ; * p<0.05$ compared with non-diabetic patients). Error bars show standard errors

cells are also capable of differentiation towards the cardiomyocyte lineage, as has been shown here and by others [22-24] (Fig. 3). However, the increased proportion of 
Table 3 Cell surface markers on EDCs and CDCs from atrial and ventricular biopsies, analysed using flow cytometry

\begin{tabular}{|c|c|c|c|c|c|c|}
\hline \multirow[t]{2}{*}{ Marker } & \multicolumn{2}{|l|}{ EDCs } & \multicolumn{2}{|l|}{ CDCs } & \multicolumn{2}{|l|}{ CDCs } \\
\hline & Atrial $(n=3)$ & Ventricular $(n=3)$ & Atrial $(n=22)$ & Ventricular $(n=8)$ & Atrial group AV $(n=8)$ & Atrial group A $(n=14)$ \\
\hline CD117 (c-kit) & $4 \pm 2 \% *$ & $9 \pm 5 \% * *$ & $0.2 \pm 0.1 \% * * *$ & $0.1 \pm 0.1 \% * * *$ & $0 \% * * *$ & $0.3 \pm 0.1 \% * * *$ \\
\hline CD45 & $1.1 \pm 1.4 \%$ & $1.3 \pm 1.8 \%$ & $0 . \%$ & $0 \%$ & $0 \%$ & $0 \% * *$ \\
\hline CD31 & $2.6 \pm 1.8 \%$ & $0.6 \pm 0.4 \%$ & $2.1 \pm 0.7 \%$ & $1.3 \pm 0.4 \%$ & $1.7 \pm 0.7 \%$ & $2.3 \pm 1.3 \%$ \\
\hline CD34 & & & $1.2 \pm 0.6 \%$ & $0.6 \pm 0.5 \%$ & $0.9 \pm 0.3 \%$ & $1.4 \pm 1.0 \%$ \\
\hline CD133 & & & $0 \%$ & $0 \%$ & $0 \%$ & $0 \%$ \\
\hline CD90 & $49 \pm 32 \%$ & $54 \pm 23 \%$ & $55 \pm 5 \%$ & $46 \pm 9 \%$ & $42 \pm 9 \%$ & $63 \pm 5 \% * * *$ \\
\hline CD105 & $83 \pm 6 \%$ & $76 \pm 1 \%$ & $80 \pm 4 \%$ & $84 \pm 6 \%$ & $83 \pm 7 \%$ & $78 \pm 5 \%$ \\
\hline
\end{tabular}

Group AV indicates hearts from which ventricular CDCs were cultured, group A indicates hearts from which no ventricular CDCs could be obtained

${ }^{*} p<0.05$ compared with ventricular EDCs; $* * p<0.05$ compared with atrial EDCs; $* * * p<0.05$ compared with group AV

CD90+ cells seen in CDCs from diabetic patients and in fastgrowing CDCs may indicate that these cells contain a greater proportion of cardiac fibroblasts, as suggested by staining for
DDR2 (Fig. 3). Increased fibrosis is observed in the ischaemic [25] and diabetic heart [26] and with age [27], increasing the likelihood of culturing fibroblasts within the CDC population.
Fig. 3 Immuno-staining of CDCs. Representative confocal images from immuno-staining of atrial CDCs for actin filaments, $C D 90$, discoidin domain receptor 2 (DDR2), smooth muscle actin $(S M A)$ and troponin-T (TnnT). Cells from diabetic patients (right 2 panels) contained higher levels of the fibroblast marker DDR2 than those from non-diabetic patients (left 2 panels) and showed low expression of TnnT after treatment with differentiation medium containing dimethyl sulphoxide (DMSO) for 2 weeks. Scale bars $=50 \mu \mathrm{m}$

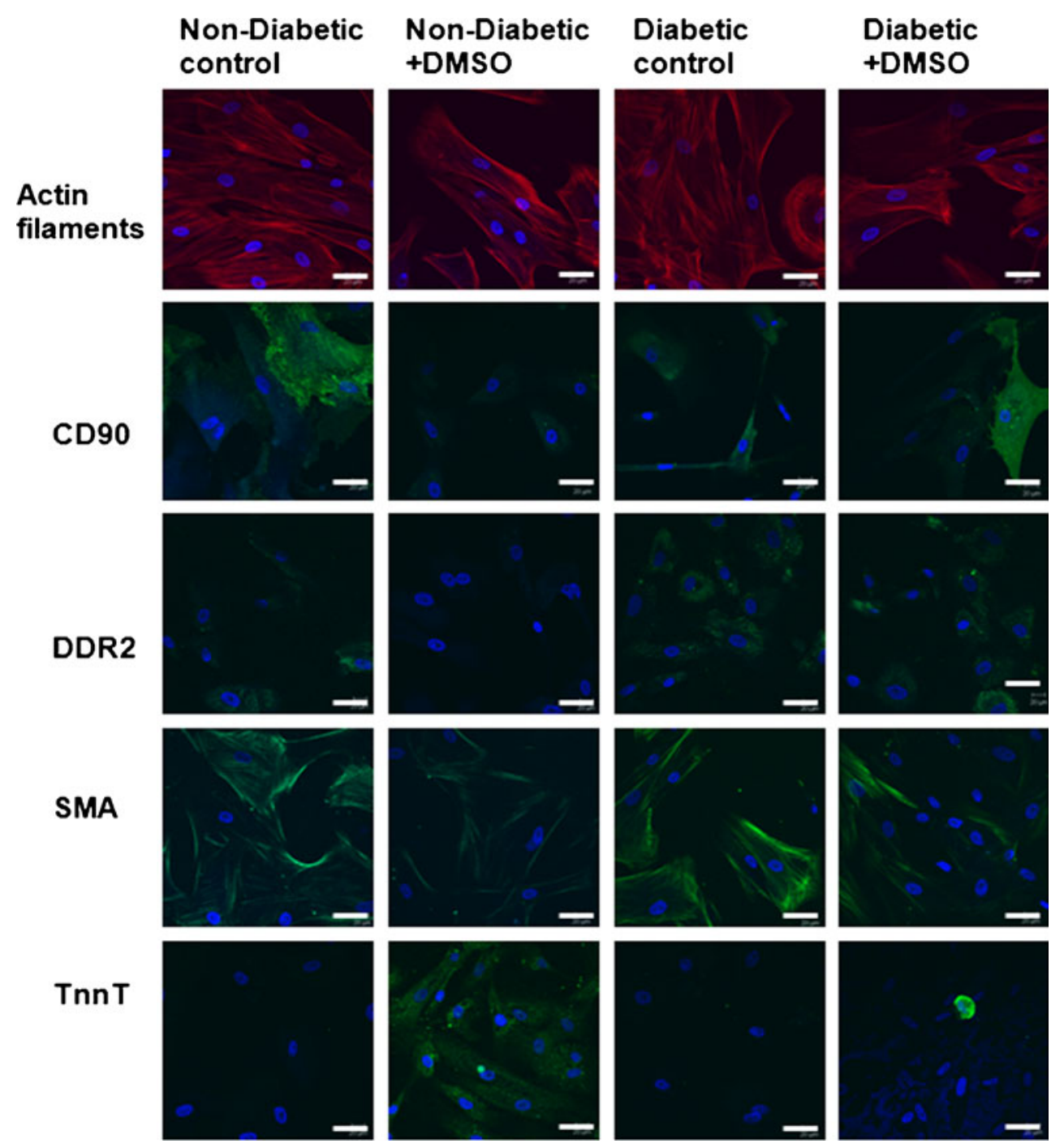




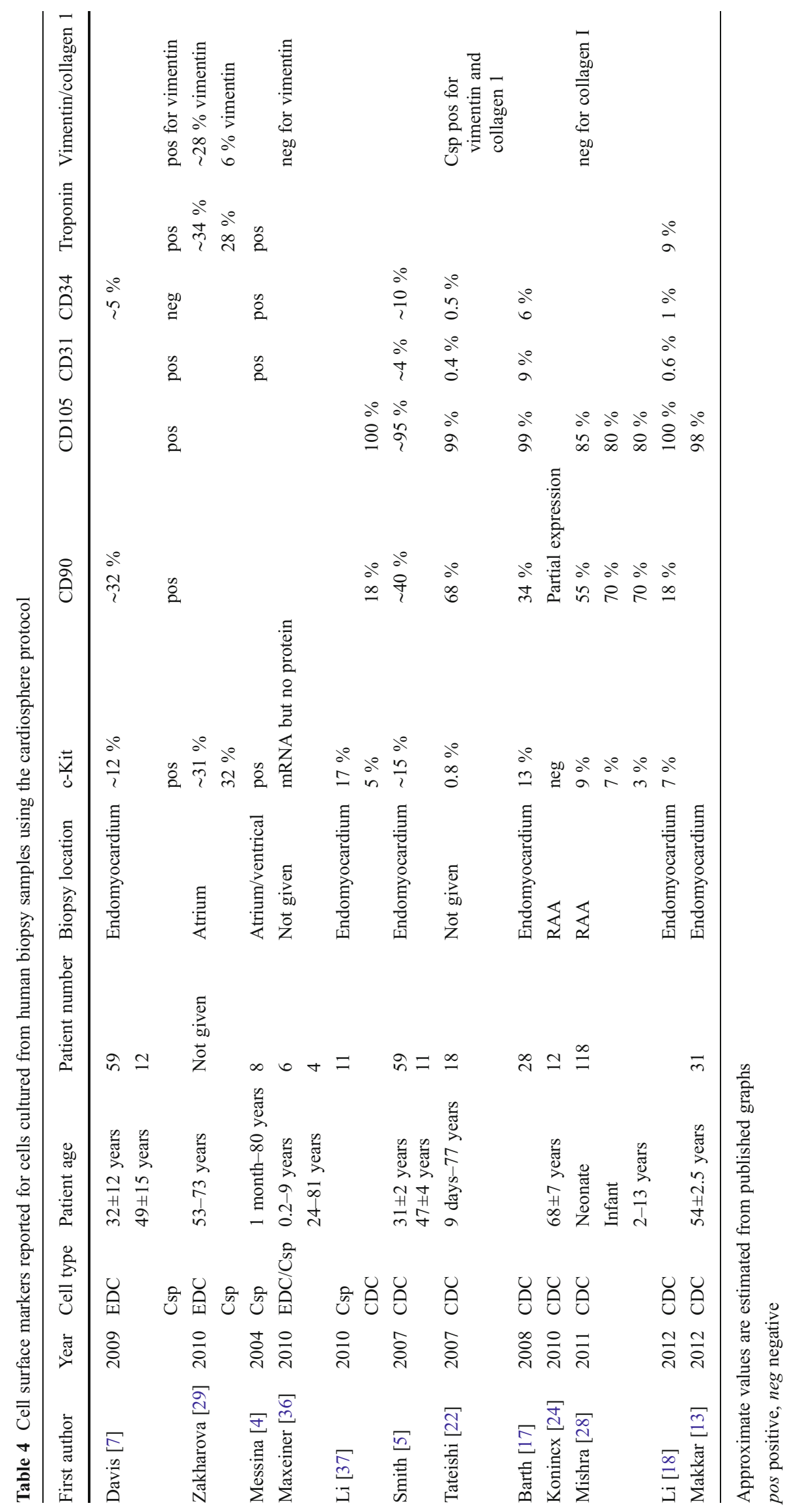


Here, we found no correlation between age and the proportion of CD90+ cells, but this may be because we did not isolate CDCs from younger, non-ischaemic hearts. Mishra et al. expanded CDCs from the hearts of children with congenital, non-ischaemic heart defects [28] which contained 55-70\% CD90+ cells and showed a decline in the number of c-kit ${ }^{+}$ cells with age (Table 4). They also showed that administration of CDCs to the infarcted mouse heart improved cardiac function compared with administration of cardiac fibroblasts, emphasising the need to minimise the cardiac fibroblast population in CDCs. Although the formation of cardiospheres was proposed to enhance the stem cell population of EDCs, many cell types have now been shown to form spheres, including myofibroblasts and bone marrow and dermal mesenchymal cells [24]. However, Zakharova et al. found that EDCs from atrial biopsies obtained from patients undergoing cardiac bypass surgery contained high levels of vimentinpositive cells, but that the proportion of these cells decreased after cardiosphere culture [29].

All atrial biopsies yielded CDCs, but we found that only 8 out of 22 ventricular epicardial biopsies yielded sufficient EDCs for CDC culture. Although the epicardium contains progenitor cells, epicardial biopsies require stimulation for significant outgrowth to occur [30]. It may be that the ventricular biopsies from which EDCs were cultured here contained significant amounts of myocardial tissue. Atrial CDCs from hearts from which no ventricular CDCs were cultured contained more CD90+ cells, as did CDCs from rapid-growing EDCs. Atrial tissue contains more fibroblasts than ventricular tissue, and atrial fibroblasts proliferate more rapidly than those from the ventricle [31]. More work is required to establish whether rapid-outgrowth EDCs contain more fibroblasts than those that take longer to migrate from the explant. It is thought that cardiac stem cells predominantly reside in the atria and apex of the heart [32], although we found significally more c-kit + cells in the small subset of EDCs from the ventricle than in those from the atrium. For the CADUCEUS trial [13], 25 million CDCs were cultured within $36 \pm 6$ days from biopsies taken from the endomyocardial septum. Interestingly, here, no atrial or epicardial biopsy yielded that number of CDCs and the calculated time to reach 25 million CDCs ranged from 47 to 278 days (Table $\mathrm{S} 1)$. For the SCIPIO trial [14], c-kit+ cells were isolated and expanded from atrial biopsies. The improvement in LVEF, measured in that study, indicated that c-kit + cells may be more potent than other cells in the EDC or CDC populations. Here, we saw a decrease in the number of c-kit+ cells between the EDC and CDC stages of expansion. Expression of c-kit has been shown to vary with time in EDCs, peaking at about 21 days after plating in rat EDCs [33], and cardiosphere culture has been reported to increase the proportion of ckit+ cells [4]. Our data suggest that this may be lost again during expansion as a monolayer of CDCs.
Clearly, further careful characterisation of CDCs expanded from human patients is essential to establish transferable and reproducible cell culture techniques necessary for large multi-centre clinical trials. Lessons from the clinical trials using bone marrow cells have shown that changes to the conditions used for isolation and storage of cells can adversely affect their therapeutic potential $[34,35]$. Thus, modification to the expansion protocol may be necessary to optimise the cell population produced from both diabetic and non-diabetic patients for maximum therapeutic effect.

Acknowledgements This work was supported by the British Heart Foundation (grant number PG/07/059/23259), the University of Melbourne Advanced Medical Science studentships (HHLC, ZMH, GNT) and by a National Institute of Health Research (NIHR) UK programme grant to NHSBT (RP-PG-0310-1001) (DS, SMW and EMR). The views expressed in this publication are those of the authors and not necessarily those of NHS, NIHR or the Department of Health.

Open Access This article is distributed under the terms of the Creative Commons Attribution License which permits any use, distribution, and reproduction in any medium, provided the original author(s) and the source are credited.

\section{References}

1. World Health Organization Statistics (2008). BHF Statistics website. http://www.heartstats.org.

2. Beltrami, A. P., Barlucchi, L., Torella, D., Baker, M., Limana, F., \& Chimenti, S. (2003). Adult cardiac stem cells are multipotent and support myocardial regeneration. Cell, 114, 763-776.

3. Oh, H., Bradfute, S. B., Gallardo, T. D., Nakamura, T., Gaussin, V., Mishina, Y., et al. (2003). Cardiac progenitor cells from adult myocardium: homing, differentiation, and fusion after infarction. Proceedings of the National Academy of Sciences of the United States of America, 100, 12313-12318.

4. Messina, E., De Angelis, L., Frati, G., Morrone, S., Chimenti, S., Fiordaliso, F., et al. (2004). Isolation and expansion of adult cardiac stem cells from human and murine heart. Circulation Research, 95, 911-921.

5. Smith, R. R., Barile, L., Cho, H. C., Leppo, M. K., Hare, J. M., Messina, E., et al. (2007). Regenerative potential of cardiospherederived cells expanded from percutaneous endomyocardial biopsy specimens. Circulation, 115, 896-908.

6. Carr, C. A., Stuckey, D. J., Tan, J. J., Tan, S. C., Gomes, R. S., Camelliti, P., et al. (2011). Cardiosphere-derived cells improve function in the infarcted rat heart for at least 16 weeks - an MRI study. PloS One, 6, e25669. doi:10.1371/journal.pone.0025669.

7. Davis, D. R., Zhang, Y., Smith, R. R., Cheng, K., Terrovitis, J., Malliaras, K., et al. (2009). Validation of the cardiosphere method to culture cardiac progenitor cells from myocardial tissue. PloS One, 4, e7195. doi:10.1371/journal.pone.0007195.

8. Andersen, D. C., Andersen, P., Schneider, M., Jensen, H. B., \& Sheikh, S. P. (2009). Murine "cardiospheres" are not a source of stem cells with cardiomyogenic potential. Stem Cells, 27, 15711581. doi:10.1002/stem.72.

9. Davis, D. R., Ruckdeschel Smith, R., \& Marban, E. (2010). Human cardiospheres are a source of stem cells with cardiomyogenic potential. Stem Cells, 28, 903-904. doi:10.1002/stem.413.

10. Kajstura, J., Gurusamy, N., Ogorek, B., Goichberg, P., ClavoRondon, C., Hosoda, T., et al. (2010). Myocyte turnover in the aging 
human heart. Circulation Research, 107, 1374-1386. doi:10.1161/ CIRCRESAHA.110.231498.

11. Rota, M., LeCapitaine, N., Hosoda, T., Boni, A., De Angelis, A., Padin-Iruegas, M. E., et al. (2006). Diabetes promotes cardiac stem cell aging and heart failure, which are prevented by deletion of the p66shc gene. Circulation Research, 99, 42-52.

12. Torella, D., Rota, M., Nurzynska, D., Musso, E., Monsen, A., Shiraishi, I., et al. (2004). Cardiac stem cell and myocyte aging, heart failure, and insulin-like growth factor-1 overexpression. Circulation Research, 94, 514-524.

13. Makkar, R. R., Smith, R. R., Cheng, K., Malliaras, K., Thomson, L. E., Berman, D., et al. (2012). Intracoronary cardiospherederived cells for heart regeneration after myocardial infarction (CADUCEUS): a prospective, randomised phase 1 trial. Lancet. doi:10.1016/S0140-6736(12)60195-0.

14. Bolli, R., Chugh, A. R., D'Amario, D., Loughran, J. H., Stoddard, M. F., Ikram, S., et al. (2011). Cardiac stem cells in patients with ischaemic cardiomyopathy (SCIPIO): initial results of a randomised phase 1 trial. Lancet, 378, 1847-1857. doi:10.1016/S0140-6736(11)61590-0.

15. Tan J.J., Carr C.A., Stuckey D.J., Ellison G.M., Messina E., Giacomello A., Clarke K.(2011). Isolation and expansion of cardiosphere-derived stem cells. Current Protocols in Stem Cell Biology 2C 3.12.

16. Johnston, P. V., Sasano, T., Mills, K., Evers, R., Lee, S. T., Smith, R. R., et al. (2009). Engraftment, differentiation, and functional benefits of autologous cardiosphere-derived cells in porcine ischemic cardiomyopathy. Circulation, 120, 1075-1083. doi:10.1161/ CIRCULATIONAHA.108.816058.

17. Barth, A. S., Kizana, E., Smith, R. R., Terrovitis, J., Dong, P., Leppo, M. K., et al. (2008). Lentiviral vectors bearing the cardiac promoter of the $\mathrm{Na}+-\mathrm{Ca} 2+$ exchanger report cardiogenic differentiation in stem cells. Molecular Therapy, 16, 957-964. doi:10.1038/mt.2008.30.

18. Li, T. S., Cheng, K., Malliaras, K., Smith, R. R., Zhang, Y., Sun, B., et al. (2012). Direct comparison of different stem cell types and subpopulations reveals superior paracrine potency and myocardial repair efficacy with cardiosphere-derived cells. Journal of the American College of Cardiology, 59, 942-953. doi:10.1016/j.jacc.2011.11.029.

19. Bearzi, C., Rota, M., Hosoda, T., Tillmanns, J., Nascimbene, A., De Angelis, A., et al. (2007). Human cardiac stem cells. Proceedings of the National Academy of Sciences of the United States of America, 104, 14068-14073.

20. Gambini, E., Pompilio, G., Biondi, A., Alamanni, F., Capogrossi, M. C., Agrifoglio, M., et al. (2010). C-kit+ cardiac progenitors exhibit mesenchymal markers and preferential cardiovascular commitment. Cardiovascular Research, 89, 362-373. doi:10.1093/cvr/cvq292.

21. Torella, D., Ellison, G. M., Mendez-Ferrer, S., Ibanez, B., \& NadalGinard, B. (2006). Resident human cardiac stem cells: role in cardiac cellular homeostasis and potential for myocardial regeneration. Nature Clinical Practice. Cardiovascular Medicine, 3(Suppl 1), S8-S13.

22. Tateishi, K., Ashihara, E., Honsho, S., Takehara, N., Nomura, T., Takahashi, T., et al. (2007). Human cardiac stem cells exhibit mesenchymal features and are maintained through Akt/GSK-3beta signaling. Biochemical and Biophysical Research Communications, 352, 635-641. doi:10.1016/j.bbrc.2006.11.096.

23. Gaetani, R., Ledda, M., Barile, L., Chimenti, I., De Carlo, F., Forte, E., et al. (2009). Differentiation of human adult cardiac stem cells exposed to extremely low-frequency electromagnetic fields. Cardiovascular Research, 82, 411-420. doi:10.1093/cvr/cvp067.
24. Koninckx, R., Daniels, A., Windmolders, S., Carlotti, F., Mees, U., Steels, P., et al. (2010). Mesenchymal stem cells or cardiac progenitors for cardiac repair? A comparative study. Cellular and Molecular Life Sciences. doi:10.1007/s00018-010-0560-y.

25. Camelliti, P., Borg, T. K., \& Kohl, P. (2005). Structural and functional characterisation of cardiac fibroblasts. Cardiovascular Research, 65, 40-51. doi:10.1016/j.cardiores.2004.08.020.

26. Chen, S., Evans, T., Mukherjee, K., Karmazyn, M., \& Chakrabarti, S. (2000). Diabetes-induced myocardial structural changes: role of endothelin-1 and its receptors. Journal of Molecular and Cellular Cardiology, 32, 1621-1629. doi:10.1006/jmcc.2000.1197.

27. Gramley, F., Lorenzen, J., Knackstedt, C., Rana, O. R., Saygili, E., Frechen, D., et al. (2009). Age-related atrial fibrosis. Age (Dordrecht, Netherlands), 31, 27-38. doi:10.1007/s11357-008-9077-9.

28. Mishra, R., Vijayan, K., Colletti, E. J., Harrington, D. A., Matthiesen, T. S., Simpson, D., et al. (2011). Characterization and functionality of cardiac progenitor cells in congenital heart patients. Circulation, 123, 364-373. doi:10.1161/CIRCULATIONAHA.110.971622.

29. Zakharova, L., Mastroeni, D., Mutlu, N., Molina, M., Goldman, S., Diethrich, E., et al. (2010). Transplantation of cardiac progenitor cell sheet onto infarcted heart promotes cardiogenesis and improves function. Cardiovascular Research. doi:10.1093/cvr/cvq027.

30. Smart, N., Risebro, C. A., Melville, A. A., Moses, K., Schwartz, R. J., Chien, K. R., et al. (2007). Thymosin beta4 induces adult epicardial progenitor mobilization and neovascularization. Nature, 445, 177-182.

31. Burstein, B., Libby, E., Calderone, A., \& Nattel, S. (2008). Differential behaviors of atrial versus ventricular fibroblasts: a potential role for platelet-derived growth factor in atrial-ventricular remodeling differences. Circulation, 117(13), 1630-1641. doi:10.1161/ CIRCULATIONAHA.107.748053.

32. Urbanek, K., Cesselli, D., Rota, M., Nascimbene, A., De Angelis, A., Hosoda, T., et al. (2006). From the Cover: stem cell niches in the adult mouse heart. Proceedings of the National Academy of Sciences of the United States of America, 103, 9226-9231.

33. Davis, D. R., Kizana, E., Terrovitis, J., Barth, A. S., Zhang, Y., Smith, R. R., et al. (2010). Isolation and expansion of functionally-competent cardiac progenitor cells directly from heart biopsies. Journal of Molecular and Cellular Cardiology, 49, 312-321. doi:10.1016/ j.yjmec.2010.02.019.

34. Assmus, B., Tonn, T., Seeger, F. H., Yoon, C. H., Leistner, D., Klotsche, J., et al. (2010). Red blood cell contamination of the final cell product impairs the efficacy of autologous bone marrow mononuclear cell therapy. Journal of the American College of Cardiology, 55, 1385-1394. doi:10.1016/j.jacc.2009.10.059.

35. Seeger, F. H., Tonn, T., Krzossok, N., Zeiher, A. M., \& Dimmeler, S. (2007). Cell isolation procedures matter: a comparison of different isolation protocols of bone marrow mononuclear cells used for cell therapy in patients with acute myocardial infarction. European Heart Journal, 28, 766-772.

36. Maxeiner, H., Krehbiehl, N., Muller, A., Woitasky, N., Akinturk, H., Muller, M., et al. (2010). New insights into paracrine mechanisms of human cardiac progenitor cells. European Journal of Heart Failure, 12(7), 730-737.

37. Li, T. S., Cheng, K., Lee, S. T., Matsushita, S., Davis, D., Malliaras, K., et al. (2010). Cardiospheres recapitulate a niche-like microenvironment rich in stemness and cell-matrix interactions, rationalizing their enhanced functional potency for myocardial repair. Stem Cells, 28(11), 2088-2098. 